Disclosure of Interest: None declared DOI: 10.1136/annrheumdis-2017-eular.3815

\section{AB1072 THE DEVELOPMENT OF ULTRASOUND SEMIOTICS OF DEFEATS OF THE JOINTS IN RHEUMATOID ARTHRITIS}

V. Sirotka ${ }^{1,1}$, U. Sirotka ${ }^{2}$, A. Litvyakov ${ }^{1} .{ }^{1}$ Department of Internal Diseases No. 1; ${ }^{2}$ Department of Traumatology, Vitebsk State Medical University, VITEBSK, Belarus

Background: Differential diagnosis of rheumatoid arthritis today is challenging in cases of atypical clinical and laboratory picture arthritis [1]. Often the use of standard $\mathrm{x}$-ray is not informative for the first two years of the disease. Erosive joint damage detected by the standard X-ray only after 2 years from the onset of the disease and only $36 \%$ of cases (M. Bukhari [et al., 2001), while the degree of articular destruction progresses with time and is correlated with a decrease in joint function.

Objectives: Development ultrasound semiotics for the diagnosis of rheumatoid arthritis using ultrasonic method of investigation of the joints.

Methods: We studied 113 patients with RA and 30 with no articular pathology a control group (CG)

In the group of patients with RA - 88 people were women $(79,7 \%), 35$ people $(20,3 \%)$ were men; the median age was 40.3 years $(33-46)$, and the median duration of current RA -4 years $(1,75-10)$.

The diagnosis of RA was established according to modified ACR criteria of 1987. The activity of the inflammatory process of the I degree was $19(27,5 \%)$ patients, II $-36(52,2 \%)$, III in 14 (20.3\%).

The control group was the patients medical history and clinically at the time of inspection there was no symptoms of the joints. Among them 15 men (50\%) and 15 women $(50 \%)$. The median age in the CG was 38.5 years (33-48)

All patients were multiplescale dynamic study II, V metacarpophalangeal and wrist joints by the ultrasonic device expert class using a sensor with a frequency of $12 \mathrm{MHz}$.

Results: Patients from the control group by ultrasound examination of the joints, we visualized the articular surfaces of the bones in the form of hyperechoic structures with clear smooth contours, homogeneous echostructure; the synovium is not visualised or she had homogeneous echostructure and a thickness of not more than $2.9 \mathrm{~mm}$; the tendon was determined in the form of a hyperechogenic bundle, of a thickness not exceeding $1.5 \mathrm{~mm}$.

Patients with RA identified the following ultrasound signs of lesions of the joints: focal pannus (96,6\%) - area of pathologically altered synovial membrane thickness of more than $3 \mathrm{~mm}$ with a "tumor-like" invasive growth and the presence of pathological vascularization (indirect signs of neoangiogenesis) detected when using Doppler on the erosion pannus; thinning synovia outside erosion (99\%); erosion, pannus $(99 \%)$; combined erosion $(96 \%)$; the erosion of inflammation: acute $(45.6 \%)$ and chronic $(89 \%)$; moderate synovitis $(89,4 \%)$; swelling of periarticular soft tissues $(88,4 \%)$; tenosynovitis $(67,6 \%)$; periarticular effusion $(66,9 \%)$; positive "pain test" in $6 \%$ of cases under ultrasound control.

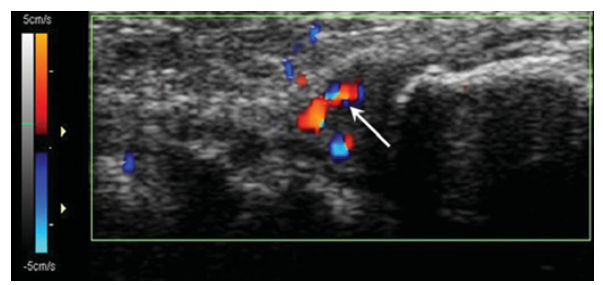

Conclusions: Given the results obtained, we have developed ultrasonic diagnostic criteria of RA.

Diagnostic criteria for rheumatoid arthritis:

1. Pannus with pathological vascularization

2. Thinning synovia outside of the pannus:

3. Erosion of the articular surface of the bone (pannus, associated erosion/erosion inflammation);

4. Moderate synovitis;

5. Tenosynovitis;

6. Periarticular swelling/effusion.

References:

[1] Raftery, G. Compresion of musculoskeletal ultrasound practices of a rheumatologist and a radiologist. G. Raftery, G. Hide, D. Kane. Rheumatology. 2007;232(3):519-522.

Disclosure of Interest: None declared

DOI: 10.1136/annrheumdis-2017-eular.2068

\section{AB1073 D-DIMER AS AN EARLY MARKER IN PATIENTS WITH LUPUS MESENTERIC VASCULITIS}

X. Ma, X. Feng, H. Wang, B. Hua, L. Sun. Rheumatology, Drum Tower Hospital, Nanjing University School of Medicine, Nanjing, China

Background: Gastrointestinal manifestations are common in systemic lupus erythematosus (SLE) patients. Lupus mesenteric vasculitis (LMV) is a major cause of acute abdominal pain in SLE patients. No early serum marker contributes to the diagnosis of lupus mesenteric vasculitis.

Objectives: The aim of this study was to investigate clinical significance of serum D-dimer level as an early diagnosis marker of LMV patients.

Methods: The 57 systemic lupus erythematosus patients were retrospectively analyzed and classified into LMV group $(n=19)$ and Non-LMV group $(n=38)$ between May 2010 and January 2016. The serum D-dimer level was measured on the first day after SLE patients presented acute abdomen as well as imaging, other laboratory-testing parameters, and SLEDAI during the same period. The maximum and mean D-dimer values were analyzed and compared with other potential markers for diagnosis of LMV. The correlation of D-dimer level with other potential severity markers and inflammation parameters were also studied.

Results: Both maximum and mean D-dimer level on the first day of presentation of acute abdomen were significantly higher in LMV patients. The D-dimer level was correlated well with L-lactate and SLEDAI. In addition, D-dimer level was detected poor correlation with white blood cell count and C-reactive protein level. Conclusions: D-dimer level could be an effective and early serum diagnosis marker of LMV.

Disclosure of Interest: None declared

DOI: 10.1136/annrheumdis-2017-eular.3045

\section{AB1074 THE TYPES OF EROSIVE LESIONS OF JOINTS IN RHEUMATOID ARTHRITIS}

V. Sirotka $^{1}$, U. Sirotka ${ }^{2}$, A. Litvyakov ${ }^{1} .{ }^{1}$ Dept. of Internal Diseases No. 1, Vitebsk State Medical University, VITEBSK; ${ }^{2}$ Dept. of Traumatology, Orthopedics and Military Field Surgery, Vitesbek State Medical University, Vitesbek, Belarus

Background: Early diagnosis of erosive lesions in rheumatoid arthritis (RA) remains today an important task, especially in the absence of specific laboratory markers. Promising research aimed at studying the informative instrumental diagnostic methods (ultrasound, $\mathrm{Rg}, \mathrm{MRI}$ ) to identify the characteristics of erosive joint damage in patients with RA [1].

Objectives: To study diagnostic possibilities of instrumental methods to identify the species of erosive joint damage in patients with RA.

Methods: We examined 104 patients with RA. Among patients of the 1st group were women $81(77.9 \%)$, men $-23(22,1 \%)$, average age was $38 \pm 12.1$ years. Diagnosis of rheumatoid arthritis was exhibited with the EULAR diagnostic criteria [2] and the ACR [3]. All patients were Rg-graphy, ultrasound and MRI of the hands. Statistical processing of the information package.

Results: Erosive lesion of joints at RA is presented by the proliferation-caused erosion (erosion of the pannus) in combination with the development of the focal pannus with vascularization and inflammatory-destructive erosion (true erosion inflammation) outside the pannus (image 1). In the study the true erosion of inflammation of the articular surface of the bone ultrasound method identified at $87.9 \%$ of the joints in RA, significantly higher $(p<0,0001)$ than in $34 \%$ of the joints in Rg-study; erosion pannus identified in $99.2 \%$ of the joints in patients with RA by means of ultrasonography, was significantly higher $(p<0,0001)$ than $24.3 \%$ of the joints in the Rg-study. So erosion from the focal invasive growth of pannus, associated erosion, erosion, acute and chronic inflammation of the articular surface of the bone in patients with RA by ultrasonography were visualized significantly more often $(p<0,0001)$ than in $\mathrm{Rg}$, which allowed to define only the fact of presence of erosive lesions of the joints, but not allowed to determine the erosive lesions. The sensitivity of ultrasound accounted for $97.9 \%(95 \% \mathrm{Cl}$ : $97,7-98,1 \%)$; specificity - of $95.7 \%(95 \% \mathrm{Cl}$ : of $95.5-95.9$ per cent). And in Rtg-graphy sensitivity accounted for $55.3 \%$ (95\% Cl: $54,8-55,8 \%)$; the specificity - of $87.7 \%(95 \% \mathrm{Cl}: 87,4-88 \%)$

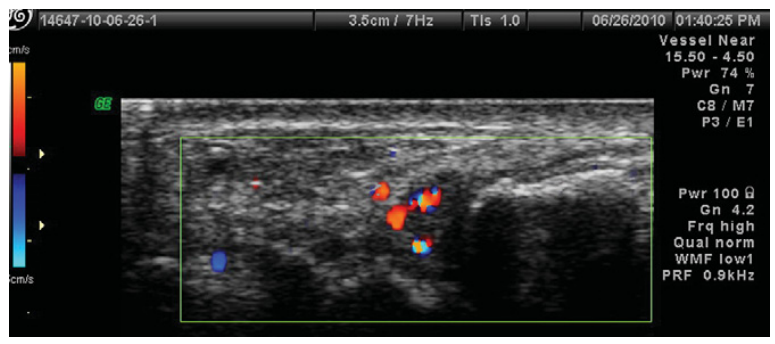

Conclusions: When comparing the results of a comprehensive study of joints in patients with RA despite the fact that $\mathrm{Rg}$ and MRI allow us to visualize and measure bone structure and pathology, ultrasound is only allowed to identify two types of erosive lesions of the joints: the true erosion inflammation and erosion of the pannus.

References:

[1] Sirotka V. Cliniko-tool differential diagnostics erosive lesions of joints at patients with rhematoid and reactive arthritis. V. Sirotka, A. Litvyakov. Vedecky Prumysl Evropskeno Kontinentu-2013: Materialy IX Mezinarodni Vedecko-Prakticka Conference, Praha, 27 Listopadu - 05 Prosincu 2013 rocu. Praha Publishing House "Education and Science". Praha, 2013. pp. 23-24.

[2] 2010 Rheumatoid Arthritis Classification Criteria: an American College of 